Check for updates

Cite this: Chem. Commun., 2017, 53, 10622

Received 26th June 2017, Accepted 30th August 2017 DOI: $10.1039 / \mathrm{c} 7 \mathrm{cc} 04944 \mathrm{~g}$ rsc.li/chemcomm

\section{In operando studies on the electrochemical oxidation of water mediated by molecular catalysts}

\begin{abstract}
Dennis G. H. Hetterscheid (ID)
Homogeneous reactions in general are relatively easy to study with respect to heterogeneous systems since all catalytic sites are uniform and can be addressed simultaneously. The latter feature is fully out of the window in an electrochemical context, where only the few catalytic species that are sufficiently close to the electrode undergo redox reactions. Especially in the water oxidation reaction where harsh reaction conditions are employed, a clear picture of what is the active species, what products are formed, how one can steer this, and how it all depends on the exact reaction conditions is important to be able to fully unravel the key reaction paths. The combination of electrochemical experiments with on-line detection of the catalytic species and reaction products is a powerful approach to successfully address these questions. Recently, a significant progress has been made in on-line studies on molecular water oxidation catalysts during electrochemical experiments. These are reviewed here.
\end{abstract}

\title{
Introduction
}

A better fundamental understanding of the oxygen evolution reaction is crucial to develop more active, more efficient and more robust catalysts that are necessary for our future energy infrastructure that ideally is based fully on renewables. ${ }^{1}$

Leiden Institute of Chemistry, Leiden University, P.O. Box 9502, 2300 RA Leiden, The Netherlands. E-mail: d.g.h.hetterscheid@chem.leidenuniv.nl;

Fax: +31 (o)71 527 4451; Tel: +31 (o)71 5274545

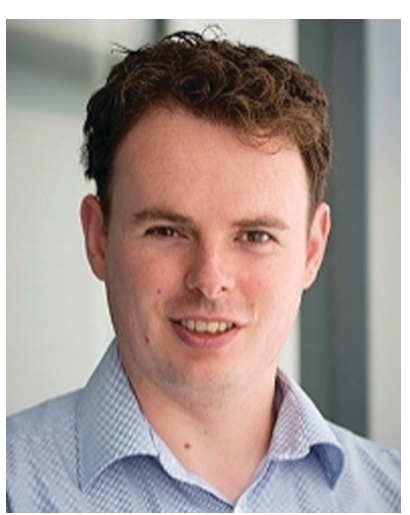

Dennis G. H. Hetterscheid

Dennis Hetterscheid obtained his PhD from the Radboud University of Nijmegen under the supervision of Prof. Bas de Bruin. He then moved to the Massachusetts Institute of Technology where he worked in the lab of Prof. Richard $R$. Schrock, and to the University of Amsterdam where he worked with Prof. Joost N. H. Reek. Since 2013 Dennis has been an assistant professor in physical chemistry of sustainable energy at Leiden University. The main research theme in his group is to understand and mimic bioinorganic multi-electron processes that are relevant to a future energy infrastructure.
To make such progress a clear understanding of the relationship between the catalyst structure, in terms of both geometry and electronics, and the catalytic activity is extremely useful. Since catalyst modification reactions are likely to occur under the oxidative conditions that are necessary to split water, it is important to actually verify the structure of the true active species. $^{2-4}$ Especially experiments where the appearance and disappearance of transient species are monitored under operando conditions and are linked to the observed product formation and reaction kinetics are very insightful.

\section{In operando studies under meaningful conditions}

Typically sacrificial reagents, such as cerium(Iv) ammonium nitrate or periodate, are used to study molecular water oxidation catalysts. ${ }^{5}$ Especially in the area of molecular ruthenium catalysts valuable and very detailed mechanistic information was gathered using these sacrificial reagents. ${ }^{6,7}$ In the case of first row transition metals, but also in the case of iridium based water oxidation catalysts, it is far less clear what pathways are taking place in the presence of sacrificial reagents. Recent reports where cerium(Iv) and periodate appear to react via oxygen atom transfer rather than electron transfer reactions, ${ }^{8-10}$ ambiguity regarding the actual structure of cerium(Iv) in aqueous solutions, ${ }^{11}$ and observations where cerium(Iv) coordinates to the active species ${ }^{12}$ or is incorporated into nanoparticle materials formed from the molecular precatalyst ${ }^{13}$ suggest that the observed reactivity may be strongly dependent on the presence of the sacrificial reagent. Moreover numerous reports illustrate that the structure of the catalytic species and the observed 
catalytic activity are strongly dependent on the applied reaction conditions. ${ }^{4,14,15}$ This illustrates the sheer importance of determining the design principles of molecular catalysts under more meaningful conditions. Considering that sooner or later water oxidation catalysis must occur at an electrode somehow, either in an electrolysis reaction or in an artificial leaf type application, investigation of the water oxidation reaction at the electrode interface under well-defined conditions appears to be a more valid approach to study the water oxidation reaction.

In operando studies of homogeneous redox catalysts in combination with electrochemistry is not straightforward to carry out, since only catalytic species very close to the electrode surface become catalytically active, while the bulk of the material in solution remains inactive. It is therefore important to sample at the electrode interface using non-standard equipment. Recently a series of in operando studies and techniques have appeared in the literature to study molecular catalysts for the water oxidation reaction in an electrochemical context. These studies have led to several new insights and are reviewed here. This review is categorized into in operando studies to (1) identify the homogeneity of the catalytic species, (2) detect the reaction product and (3) detect catalytic intermediates.

\section{Distinguishing between homogeneous and heterogeneous catalysis}

For any catalytic reaction mediated by a homogeneous catalyst it is important to rule out that heterogeneous (nano)particles are the true active species. This especially holds when very harsh reaction conditions are applied. Verification that the structure of the material present after catalysis is identical to the (pre)catalyst typically is a good first step to establish that the anticipated catalyst is the true active species. In particular during electrochemical reactions in the presence of a homogeneous catalyst this is not straightforward. In such an electrochemical setup the actual catalytic reaction and all related phenomena will only occur at the electrode interface and not in the bulk solution. Formation of heterogeneous material should therefore be established at the electrode interface, and not just in the bulk solution using e.g. dynamic light scattering.

Examination whether a deposit has formed at the electrode can be done in an ex situ manner by taking out the electrode from the solution, carefully rinsing it and observing whether any catalytic activity is retained when the electrode is placed into a fresh electrolyte solution devoid of any dissolved (pre)catalyst. However, it remains difficult to distinguish whether the material on the electrode is dip coated or truly deposited under oxidative conditions and reversible processes can easily be overlooked (vide infra).

Electrochemical crystal quartz microbalance (EQCM) experiments can be very insightful as this technique allows one to follow the deposition of electrodeposited material on-line, allowing one to connect deposition of material to particular features in the current-potential diagram, time and the precise reaction conditions.

\section{Microbalance techniques}

EQCM allows one to measure mass changes at the electrode in the order of nanograms per square centimetre surface area. This relates to deposition of submonolayer amounts of material ${ }^{16}$ and allows for detection of e.g. the coordination of solvent molecules to deposited complexes. ${ }^{17}$

The quartz crystal is wedged between two metal electrodes and brought to vibration due to an alternating electric field, causing elastic deformation of the quartz crystal. Since one of the electrodes serves as the working electrode, deposition of material at the working electrode results in a frequency change of the acoustic wave in the quartz electrode according to the Sauerbrey equation (eqn (1)) where $\Delta f$ is the change in frequency, $f_{0}$ is the frequency of the quartz crystal prior to the mass change, $\Delta m$ is the change of mass, $A$ is the piezocatalytic surface area, $\rho_{\mathrm{q}}$ is the density of quartz and $\mu_{\mathrm{q}}$ is the shear modulus. ${ }^{16,18}$

$$
\Delta f=-2 f_{0}^{2} \frac{\Delta m}{A \sqrt{\mu_{\mathrm{q}} \rho_{\mathrm{q}}}}
$$

In practice the relationship between $\Delta f$ and $\Delta m$ can be calibrated by underpotential deposition of e.g. $\mathrm{Pb}^{2+}$ where the amount of electrons passed through the electrode and the mass gain are correlated. ${ }^{19,20}$ One should be aware that eqn (1) assumes that the acoustic wave propagates in the same manner in quartz and the deposited material. Moreover, it has been shown that also viscosity and hydrophobic effects can result in significant deviations of $\Delta f$. Interpretation of EQCM data therefore is not straightforward.

The use of EQCM was introduced in the field of homogeneous water oxidation catalysis by the groups of Crabtree, Brudvig and D'Souza in $2011 .^{21}$ Electrolysis in the presence of $\left[\operatorname{Ir}\left(\mathrm{Cp}^{*}\right)\left(\mathrm{OH}_{2}\right)_{3}\right] \mathrm{SO}_{4}$ $\left(\mathrm{Cp}^{*}=\right.$ pentamethylcyclopentadienyl) results in the formation of a deposit onto the electrode surface, ${ }^{22}$ which is clearly visible by EQCM analysis (Fig. 1). ${ }^{21,23}$ The catalytic activity of the electrode increases upon repetitive scanning, illustrated by a growing oxidative current. This is the result of more and more material depositing on the electrode and the resulting increased surface area of the heterogeneous catalyst. ${ }^{22}$ Ex situ analysis of the deposited materials by X-ray techniques including Extended X-ray Absorption Fine Structure (EXAFS) spectroscopy and High-Energy X-ray Scattering (HEXS) revealed that the material deposited on the electrode is best described as very small amorphous iridium clusters with a very high surface area. ${ }^{24}$ NMR experiments in which iridium $\mathrm{Cp}^{*}$ complexes were treated with sacrificial reagents showed that the $\mathrm{Cp}^{*}$ ligand is not stable under oxidative conditions. It was found that $\left[\operatorname{Ir}^{\mathrm{III}} \mathrm{Cp}{ }^{*}(\mathrm{bzpy}) \mathrm{NO}_{3}\right]$ in the presence of periodate results in stepwise incorporation of oxygen into the $\mathrm{Cp}^{*}$ framework, ${ }^{25,26}$ and upon treatment of $\left[\operatorname{Ir}^{\mathrm{III}} \mathrm{Cp}^{*}(\right.$ pyalc $\left.) \mathrm{Cl}\right]$ with periodate the $\mathrm{Cp}^{*}$ ligand was lost altogether $\left(\right.$ bzpy $=2$-benzoylpyridine, pyalc $=2$ - $\left(2^{\prime}\right.$-pyridyl $)-2$-propanolate $) \cdot{ }^{27}$

The deposition of material on the electrode is typically triggered by an oxidation reaction and therefore requires a certain applied potential. Consequently, deposition can be observed as a continuous growth when the potential is kept constant above this potential limitation ${ }^{28}$ and can be observed as a stepped plot when 

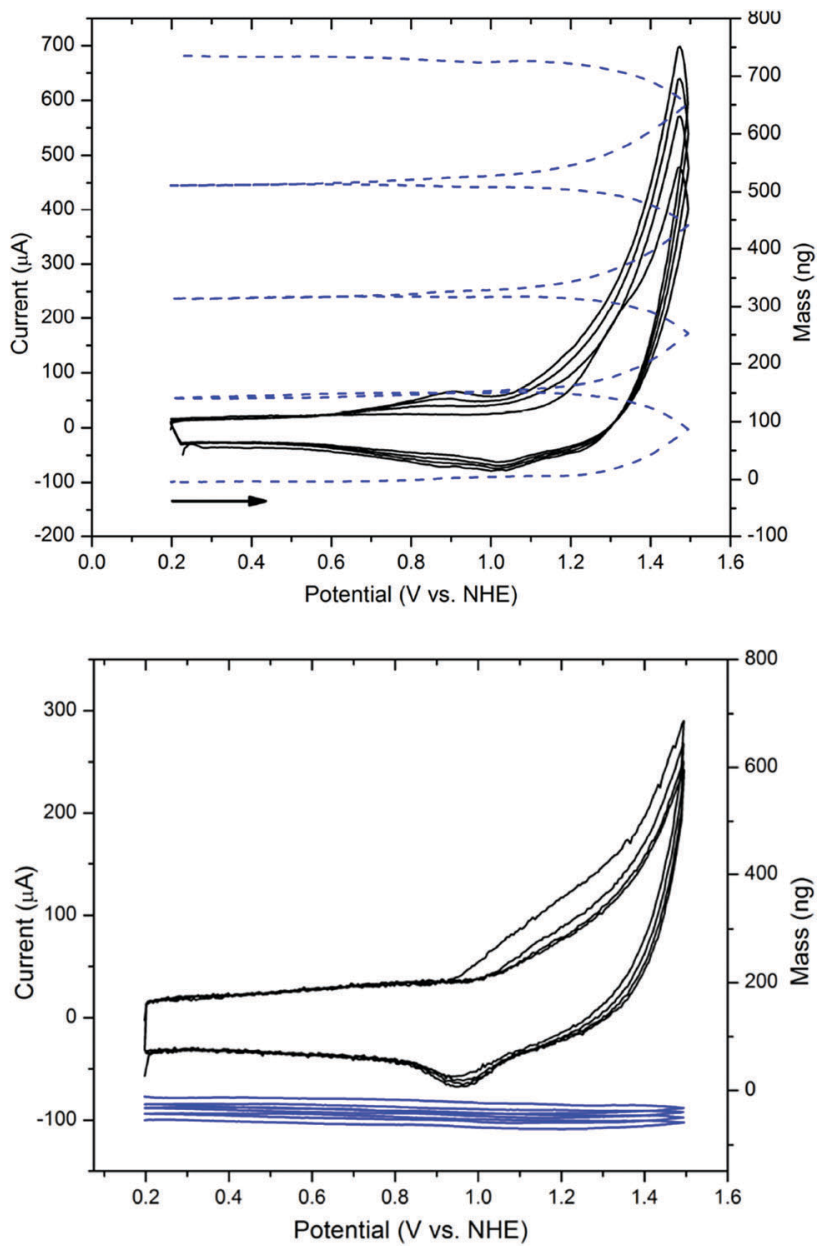

Fig. 1 Difference in the EQCM response of a deposition formed from the precursor $\left[\mathrm{Ir}(\mathrm{Cp} *)\left(\mathrm{OH}_{2}\right)_{3}\right] \mathrm{SO}_{4}$ (top) and formation of a homogeneous catalyst from the precursor $\left[\mathrm{Ir}\left(\mathrm{Cp}^{*}\right)\left(\right.\right.$ pyalc) $\left.\left(\mathrm{CF}_{3} \mathrm{COO}\right)\right]$ (bottom). $\dagger$ The currents are depicted in black and the mass trace in blue. Reprinted with permission from ref. 21. Copyright (2011) American Chemical Society.

the applied potential is cycled back and forth over the deposition onset potential (Fig. 1). ${ }^{21}$

The rate of deposition depends on the applied potential, time and the concentration of the precursor complex in solution. ${ }^{23}$ Also the structure of the precursor has a strong influence on the amount of material that is being deposited and at present is not fully understood. Deposition of $\left[\operatorname{Ir}(\mathrm{Cp})\left(\mathrm{OH}_{2}\right)_{3}\right] \mathrm{SO}_{4}(\mathrm{Cp}=$ cyclopentadienyl) is substantially faster at early stages of the water oxidation reaction compared to equimolar concentrations of $\left[\operatorname{Ir}\left(\mathrm{Cp}^{*}\right)\left(\mathrm{OH}_{2}\right)_{3}\right] \mathrm{SO}_{4}$, which has a very similar structure. ${ }^{23}$ Eventually, the rates of deposition reverse, which is explained by diffusion limitations of the depositing precursor complexes and oxygen bubble formation at the electrode interface under the oxidative conditions applied. These hamper in particular the deposition rates of the faster process.

Evidently, no mass changes are to be expected in the absence of a depositing (pre)catalyst, apart from slight changes that are caused by the surface restructuring of the gold working electrode, if the potential is scanned over the gold oxidation and reduction potentials. In the case of both $\left[\operatorname{Ir}\left(\mathrm{Cp}^{*}\right)(\right.$ pyalc $\left.)\left(\mathrm{CF}_{3} \mathrm{COO}\right)\right]$
(Fig. 1, bottom) and $\left[\mathrm{Ru}\left(\right.\right.$ cymene)(bipyridine) $\left.\left(\mathrm{OH}_{2}\right)\right]\left(\mathrm{NO}_{3}\right)_{2}$ deposition of metal oxide on the electrode surface was ruled out by EQCM methods. ${ }^{21,29}$ This alone does not mean that the catalyst remains intact. The iridium complex $\left[\operatorname{Ir}\left(\mathrm{Cp}^{*}\right)(\right.$ pyalc $\left.)\left(\mathrm{CF}_{3} \mathrm{COO}\right)\right]$ loses the $\mathrm{Cp}^{*}$ ligand in periodate media to produce an active water oxidation catalyst ${ }^{27}$ and it is believed to form the same active species in the electrochemically driven water oxidation. ${ }^{30} \mathrm{Ex}$ situ EXAFS and HEXS experiments revealed that in this case an iridium(v) dimer with a single bridged $\mu-\mathrm{O}$ ligand has formed. ${ }^{31}$

Besides monitoring the deposition of (pre)catalysts at the electrode surface, illustrated in the previous paragraphs, also analysis of desorption of material from the electrode can be insightful. An electrode with deposited iridium oxide, prepared from the deposition of $\left[\operatorname{Ir}\left(\mathrm{Cp}^{*}\right)\left(\mathrm{OH}_{2}\right)_{3}\right] \mathrm{SO}_{4}$, shows distinct redox waves of the +III/+IV redox couple of iridium at $1.0 \mathrm{~V}$ versus NHE ( $\mathrm{pH} 2.9), \dagger$ when it is placed in a blank electrolyte solution in the absence of further $\left[\operatorname{Ir}\left(\mathrm{Cp}^{*}\right)\left(\mathrm{OH}_{2}\right)_{3}\right] \mathrm{SO}_{4} \cdot{ }^{21}$ When the potential of the electrode is increased above $1.0 \mathrm{~V}$ an apparent increase of mass was recorded by EQCM. The observed increase in mass is the result of electrolyte and solvent uptake by the catalytic layer concerted with oxidation of the iridium sites to the +IV oxidation state. Above the onset for the oxygen evolution reaction at $1.2 \mathrm{~V}$ versus $\mathrm{RHE}(\mathrm{pH} 2.9)$ the mass of the electrode appears to decrease (Fig. 2). This effect is most likely caused by the formation of oxygen bubbles, which increase the hydrophobicity of the electrode surface. ${ }^{21}$ The + III/+IV redox couple and the catalytic current do not appear to change under these circumstances, suggesting that desorption of iridium oxide does not take place. This is in line with the reported excellent stability of iridium oxide under acidic conditions. ${ }^{32}$

When a catalytic deposit of $\left[\operatorname{Ir}\left(\mathrm{Cp}^{*}\right)\left(\mathrm{Me}_{2} \mathrm{NHC}\right)(\mathrm{OH})_{2}\right]$ at a gold electrode is treated with an electrolyte solution devoid of any $\left[\operatorname{Ir}\left(\mathrm{Cp}^{*}\right)\left(\mathrm{Me}_{2} \mathrm{NHC}\right)(\mathrm{OH})_{2}\right]$, an immediate drop of mass is observed (Fig. 2). ${ }^{28}$ Simultaneously with the loss of mass the catalytic current decreased instantaneously, suggesting that in this case all catalytic material has desorbed from the electrode surface. In line with the observed reaction kinetics, $\mathrm{pH}$ dependence of the catalytic reaction and the observed electrolyte effects, a different catalytic species must be formed in the case of $\left[\operatorname{Ir}\left(\mathrm{Cp}^{*}\right)\left(\mathrm{Me}_{2} \mathrm{NHC}\right)(\mathrm{OH})_{2}\right]$ rather than the amorphous iridium oxide layer formed by deposition of $\left[\mathrm{Ir}\left(\mathrm{CP}^{*}\right)\left(\mathrm{OH}_{2}\right)_{3}\right] \mathrm{SO}_{4}$. Deposition of $\left[\operatorname{Ir}\left(\mathrm{Cp}^{*}\right)\left(\mathrm{Me}_{2} \mathrm{NHC}\right)(\mathrm{OH})_{2}\right]$ appears to be limited to a maximum loading varying somewhere between 5 and $100 \mu \mathrm{g} \mathrm{cm} \mathrm{cm}^{-2}$ probably depending on the roughness of the electrode. Above these threshold values no further deposition seems to take place according to the EQCM studies either in cyclic voltammetry or in amperometry mode. ${ }^{28} \mathrm{Ex}$ situ analysis of these samples by EXAFS and X-ray Photoelectron Spectroscopy (XPS) shows that albeit oxidative modification reactions have occurred upon prolonged electrolysis and although carbon is displaced for oxygen in the

$\dagger$ The normal hydrogen electrode (NHE) and the reversible hydrogen electrode (RHE) are related according to $E_{\mathrm{RHE}}=E_{\mathrm{NHE}}+0.059 \times \mathrm{pH}$. Since not in all cases sufficient accurate data are available regarding the $\mathrm{pH}$, the redox potentials given in this review are referenced according to the reference scale in the original report. 

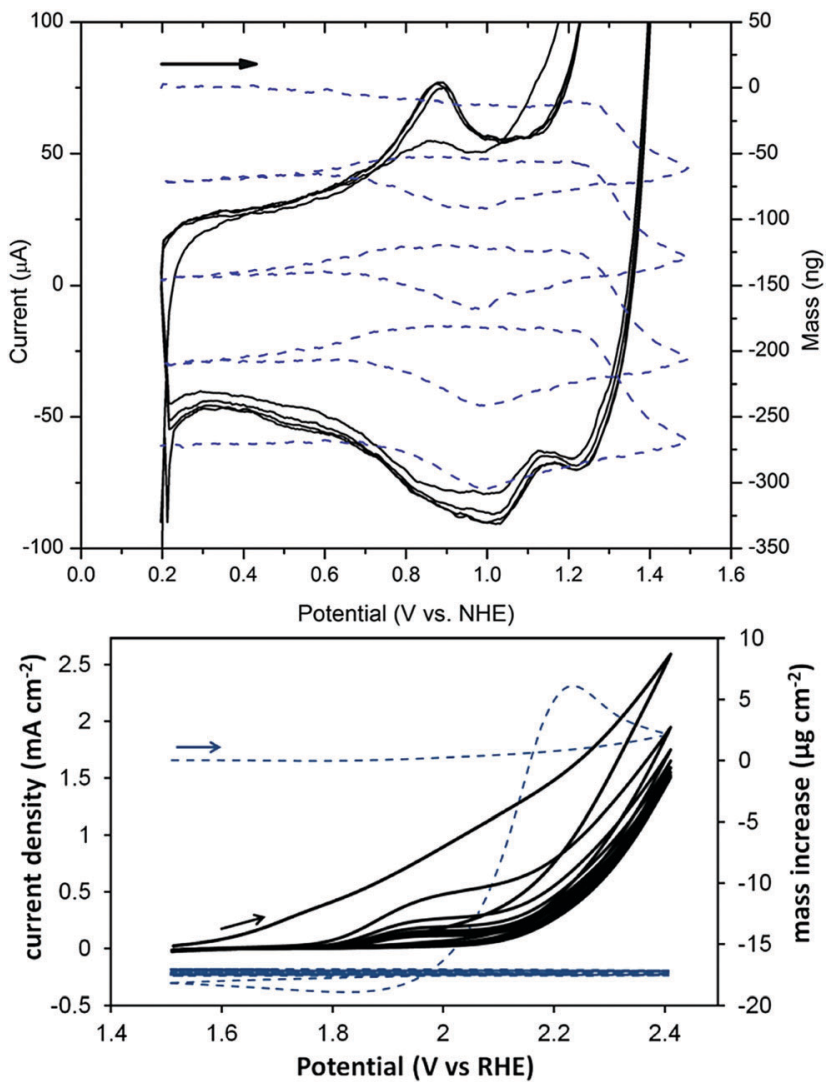

Fig. 2 Top: Example of an EQCM experiment in which the formation of oxygen bubbles appears as a reduction in mass in the case of iridium deposition from the precursor $\left[\operatorname{Ir}\left(\mathrm{Cp}^{*}\right)\left(\mathrm{OH}_{2}\right)_{3}\right] \mathrm{SO}_{4}$ in a $0.1 \mathrm{M} \mathrm{KNO}_{3}$ aqueous solution $(\mathrm{pH} 5.5)$. $\dagger$ The currents are depicted in black and the mass trace in blue. Reprinted with permission from ref. 21. Copyright (2011) American Chemical Society. Bottom: Example of an EQCM experiment in which rapid desorption of catalytic material takes place in $0.1 \mathrm{M} \mathrm{Na}_{2} \mathrm{SO}_{4}$ acidified to $\mathrm{pH}$ 1. The deposit in this case was generated by deposition of $\left[\operatorname{lr}\left(\mathrm{Cp}^{\star}\right)\left(\mathrm{Me}_{2} \mathrm{NHC}\right)(\mathrm{OH})_{2}\right]$. Reproduced from ref. 28 with permission from the PCCP Owner Societies.

direct coordination sphere of iridium, the iridium sites appear to be part of a molecular species. ${ }^{28}$ Moreover the iridium binding energies recorded by XPS analysis corresponded very well with those observed for molecular iridium(Iv) species rather than that of inorganic iridium(Iv) oxide. ${ }^{27,28,31}$

Reversible adsorption of catalytic material on the electrode was observed in the case of $\left[\operatorname{Ir}(\text { bpsa-Cy })(\mathrm{Cl})_{2}\right]^{-}$in aqueous $\mathrm{KNO}_{3}$ and was clearly visible by EQCM analysis (bpsa-Cy $=N, N^{\prime}$ (1S,2S-cyclohexane-1,2-diyl)bis(pyridine-2-sulfonamide)). ${ }^{33}$ This particular catalyst was studied at an ITO coated EQCM electrode, which resulted in slow electron transfer kinetics. Hence widely separated +III/+IV oxidation and reduction peaks were observed, both in acetonitrile and in aqueous media. Whereas in acetonitrile no deposition of material is observed, a clear mass gain was observed in an aqueous solution, even though very similar voltammetry behaviour was observed in both media. Apparently, the neutral oxidation product of anionic $\left[\operatorname{Ir}(\mathrm{bpsa}-\mathrm{Cy})(\mathrm{Cl})_{2}\right]^{-}$is well soluble in acetonitrile whereas it is not in aqueous $\mathrm{KNO}_{3}$. Upon reduction of the neutral iridium(Iv) species to the soluble anionic iridium(III) species an immediate mass loss can be observed. No electrocatalytic water oxidation activity was reported for $\left[\operatorname{Ir}(\text { bpsa-Cy })(\mathrm{Cl})_{2}\right]^{-}$, although oxygen evolution has been observed upon addition of sacrificial reagents. ${ }^{33}$

\section{Disentangling product formation from other oxidative processes}

To what extent a recorded current belongs to the oxygen evolution reaction can be verified by headspace analysis using GC in a bulk electrolysis configuration. However, when multiple features are observed in the potential-current diagram, when changes in the potential-current diagram do occur over time, or when the faradaic efficiency is not $100 \%$ (for molecular complexes it typically isn't), on-line monitoring of the formation of the actual product is essential to grasp the full picture.

\section{Mass spectrometry techniques}

The most common method to sample gaseous products for mass spectrometry analysis during electrochemical experiments is differential electrochemistry mass spectrometry (DEMS). ${ }^{34}$ The electrochemistry experiment is carried out in a flow cell that via a Teflon membrane and a steel frit, which are both permeable for gases, is connected to the mass spectrometer. The working electrode is positioned close to the Teflon membrane, whereas the reference and counter electrodes are positioned in the inlet and outlet of the flow system. Since relatively large amounts of material enter the vacuum system, the pressure is reduced by differential pumping. Due to the flow of electrolyte over the electrode, the shape of the currentpotential profile is different than in a typical cyclic voltammogram and is somewhat similar to RDE experiments. The alternative technique is on-line electrochemical mass spectrometry (OLEMS) where the inlet of the mass spectrometer is placed in close position to a working electrode in a hanging meniscus configuration. ${ }^{35}$ This approach allows for analysis of various types of electrode materials including single crystals and electrodes at which molecular water oxidation catalysts are immobilized. ${ }^{36}$ The inlet of the mass spectrometer is equipped with a Teflon membrane that is only permeable for small amounts of gaseous products that renders differential pumping unnecessary. Since the mass response depends on amongst others the exact distance between the working electrode and the inlet of the mass spectrometer, OLEMS is more of a qualitative technique rather than being well suited for quantification of the dioxygen levels. Both DEMS and OLEMS allow for real time recording of mass traces of gaseous products such as $\mathrm{O}_{2}(\mathrm{~m} / \mathrm{z}=32)$ and $\mathrm{CO}_{2}(\mathrm{~m} / \mathrm{z}=44)$ sampled in the liquid phase.

OLEMS experiments were important to establish that $c i s$-iron cyclam complexes are active in the water oxidation reaction, whereas the trans complexes are not. ${ }^{37}$ Electrolysis of water at $1.9 \mathrm{~V}$ versus $\mathrm{RHE}$ in the presence of $1.1 \mathrm{mM}\left[\right.$ cis-Fe $($ cyclam $\left.)(\mathrm{Cl})_{2}\right] \mathrm{Cl}$ resulted in the immediate formation of dioxygen. Despite the fact that OLEMS experiments typically show a lag time, the initial rate of oxygen evolution determined by mass spectrometry clearly 
showed that the turnover frequency is maximal at the very beginning of the electrolysis experiment. This suggests that water oxidation catalysis is mediated by the molecular [cis$\mathrm{Fe}($ cyclam $\left.)(\mathrm{Cl})_{2}\right] \mathrm{Cl}$ complex itself. Moreover cyclic voltammetry after electrolysis only showed the anticipated $\mathrm{Fe}^{\mathrm{II}} / \mathrm{Fe}^{\mathrm{III}}$ and $\mathrm{Fe}^{\mathrm{III}} / \mathrm{Fe}^{\mathrm{IV}}$ redox couples, further illustrating that the iron catalyst was still intact. In contrast, no evolution of dioxygen was observed in the case of the trans iron cyclam complex, despite the fact that a significant oxidative current was observed. ${ }^{37}$

Also in the case of $[\mathrm{Ru}(\mathrm{bpc})(\mathrm{cy}) \mathrm{Cl}]^{+}$an immediate evolution of dioxygen was observed by OLEMS; yet in this particular case the rate of dioxygen evolution after the initial rise decreases and stabilizes at a lower level, pointing to either a catalyst modification reaction or some inhibitory event taking place after several turnovers $\left(\mathrm{cy}=\text { cymene, bpc }=\left[2,2^{\prime} \text {-bipyridine }\right]-4,4^{\prime} \text {-dicarboxylic acid }\right)^{38}$

In contrast to the previous examples, amperometry experiments in combination with OLEMS in the presence of $\left[\mathrm{IrCl}_{3}\right.$ (picolinate)$(\mathrm{HOMe})]^{-}$did not reveal significant amounts of dioxygen in the initial stages of the electrolysis experiment. Only after several minutes significant amounts of dioxygen started to evolve. ${ }^{39}$ Vigorous evolution of dioxygen resulted in bubble formation, illustrated by the spikes on the dioxygen trace in Fig. 3. Carbon dioxide, the product of ligand degradation, on the other hand is predominantly formed in small quantities at the very early stage of the electrolysis reaction. Its formation can be traced back to oxidative events in the first cycle of a voltammetry experiment, suggesting that in this case complete degradation of the ligands is compulsory in order to obtain the oxygen evolution reaction. Ex situ XPS experiments revealed that predominantly iridium oxide is present at the stages where the highest rates of the oxygen evolution reaction were recorded. Moreover, the cyclic voltammogram at this stage in the catalytic reaction matches well with that of typical voltammograms of iridium oxide. ${ }^{40}$

During a potential sweep, one can use DEMS or OLEMS to determine the actual onset potential of the oxygen evolution reaction. In such experiments it is important to employ very low scan rates (typically $1 \mathrm{mV} \mathrm{s}^{-1}$ ) in order for the mass spectrometer to keep up with the voltammetry. And even then the bulk

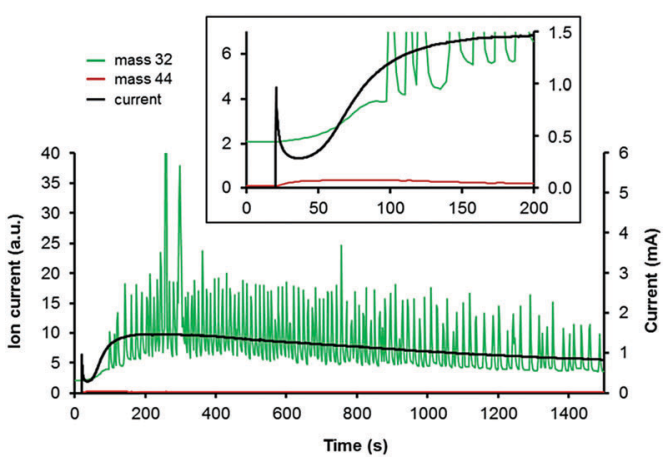

Fig. 3 Chronoamperometry in combination with OLEMS in the presence of ( $\mathrm{HpicMe})\left[\mathrm{IrCl}_{3}\right.$ (picolinate)(HOMe)] in $0.1 \mathrm{M} \mathrm{HClO}_{4}$. Depicted are the current (black), the $\mathrm{m} / \mathrm{z}=32$ trace belonging to $\mathrm{O}_{2}$ (green) and the $\mathrm{m} / \mathrm{z}=44$ trace belonging to $\mathrm{CO}_{2}$ (red). Reprinted with permission from ref. 39. Copyright (2016) American Chemical Society. of the dioxygen detected follows several seconds behind the moment the voltammetry experiment reaches its maximum potential and measured current. If formation of dioxygen is the predominant oxidative reaction, the oxygen evolution trace and the current profile should largely match, and thereby facilitate assignment of the onset of the oxygen evolution reaction.

In the case of $\left[\mathrm{Ir}\left(\mathrm{Cp}^{*}\right)\left(\mathrm{Me}_{2}-\mathrm{NHC}\right)(\mathrm{OH})_{2}\right]$ formation of dioxygen was observed by OLEMS, which matched perfectly with the current that was recorded (Fig. 4). ${ }^{36}$ Although catalyst modifications were observed by ex situ X-ray absorption spectroscopy experiments, ${ }^{28}$ no formation of carbon dioxide was detected. $[$ trans-Fe(cyclam $\left.)(\mathrm{Cl})_{2}\right]$ shows the opposite result; ${ }^{37}$ no dioxygen was recorded by OLEMS and all observed current was assigned to catalyst and/or electrode degradation and formation of $\mathrm{CO}_{2}$. In the case of $\left[\right.$ cis- $\mathrm{Fe}($ cyclam $\left.)(\mathrm{Cl})_{2}\right] \mathrm{Cl}$ an onset of $1.8 \mathrm{~V}$ was recorded for evolution of dioxygen, yet current and formation of $\mathrm{CO}_{2}$ started to show around $1.6 \mathrm{~V}$ versus $\mathrm{RHE}$, directly above the $+\mathrm{III} /+\mathrm{IV}$ redox couple of Fe. This suggests that the $+\mathrm{V}$ oxidation state of $\mathrm{Fe}$ is necessary to produce dioxygen, yet the $+\mathrm{IV}$ oxidation of $\mathrm{Fe}$ is sufficient to trigger oxidation of the ligand or the carbon electrode. Carbon electrodes produce significant amounts of background current and carbon dioxide under oxidative conditions, ${ }^{41}$ especially at low $\mathrm{pH},{ }^{42}$ which may be even further enhanced in the presence of an oxidation catalyst. ${ }^{37}$ Thus far we were unable to detect any trace of dioxygen at a bare carbon electrode below $2.0 \mathrm{~V}$ versus RHE. Gold electrodes prove to be a better choice of electrode material in combination with OLEMS in a hanging meniscus configuration, due to the absence of carbon and no formation of dioxygen below $2.0 \mathrm{~V}$ versus $\mathrm{RHE}$ (pH 1). ${ }^{43}$

DEMS was used successfully to assign the active species in water oxidation catalysis in the presence of cobalt cubane complexes. The observed catalytic current of the water oxidation reaction in the presence of $\left[\mathrm{Co}_{4} \mathrm{O}_{4}(\mathrm{OAc})_{4}(\mathrm{Py})_{4}\right]$ was significantly lower when $\left[\mathrm{Co}_{4} \mathrm{O}_{4}(\mathrm{OAc})_{4}(\mathrm{Py})_{4}\right]$ was purified prior to the electrochemical experiment by column chromatography (py = pyridine) ${ }^{41}$ Supported by electron paramagnetic resonance line broadening analysis and the results of electrochemical titrations this points to

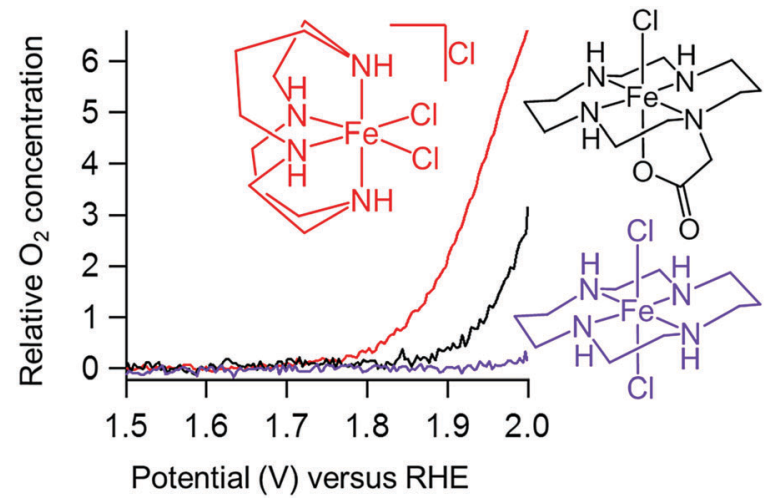

Fig. 4 Comparison of the $\mathrm{O}_{2}$ traces $(m / z=32)$ for three Fe cyclam complexes recorded via OLEMS in cyclic voltammetry mode using a PG working electrode in $0.1 \mathrm{M} \mathrm{NaClO}_{4}$. Adapted from ref. 37 with permission from the Royal Society of Chemistry. 
traces of cobalt(II) impurity in the sample that are responsible for the observed catalytic activity via formation of a heterogeneous catalyst. ${ }^{44}$ DEMS analysis of crude and purified $\left[\mathrm{Co}_{4} \mathrm{O}_{4}(\mathrm{OAc})_{4}(\mathrm{Py})_{4}\right]$ samples revealed that very little dioxygen is produced after purification, whereas substantial amounts of dioxygen were detected for the crude material. The analysis with DEMS also showed that a considerable part of the current in the case of crude $\left[\mathrm{Co}_{4} \mathrm{O}_{4}(\mathrm{OAc})_{4}(\mathrm{Py})_{4}\right]$ and especially in the case of purified $\left[\mathrm{Co}_{4} \mathrm{O}_{4}(\mathrm{OAc})_{4}(\mathrm{Py})_{4}\right]$ must be assigned to carbon dioxide formation from the electrode material rather than to evolution of dioxygen. ${ }^{41} \mathrm{It}$ should be noted that purified $\left[\mathrm{Co}_{4} \mathrm{O}_{4}(\mathrm{OAc})_{4}(\mathrm{Py})_{4}\right]$ is still catalytically active above $\mathrm{pH} 12,{ }^{45}$ and upon displacement of a bridging acetate by treatment with hydroxide ${ }^{46}$ or upon aging. ${ }^{47}$

\section{Rotating ring disk techniques}

Rotating ring disk techniques can be very powerful in on-line identification of redox active reaction products. Yet for a clear analysis it is required that the homogeneous catalyst is somehow attached to the electrode surface. In rotating disk experiments one can typically determine the equivalents of electrons that are passed through the electrode upon substrate formation via the Koutecky-Levich equation. This equation correlates the substrate flux to the current in a regime where the catalytic reaction is limited in substrate. ${ }^{48}$

In the case of water oxidation reaction, it is difficult to imagine for the reaction to run ever out of substrate. Under these circumstances the observed current becomes independent of the rotation speed ${ }^{49}$ and the use of a ring electrode becomes more important for product identification. In such an RRDE configuration catalytic water oxidation takes place at the disk electrode. Upon rotation of the disk, the reaction products of oxidation are passed over a ring electrode due to a lamella flow. At the ring a potential is applied that allows for reduction of dioxygen, allowing for quantitative analysis of the amount of oxygen that is formed at the disk (Fig. 5). In a similar manner the levels of peroxide and superoxide can be determined by selecting a ring-potential slightly above the potential where platinum is capable of reducing $\mathrm{O}_{2}$. To determine the actual amount of products the collection efficiency of the electrode, which depends on the ring-disk geometry, must be determined first using a standard reaction such as the oxidation of ferrocyanide. One has to be careful in interpreting such data; due to bubble formation at the disk, the concentration of dioxygen at the ring may not be linear with dioxygen formation at the disk. Moreover in such an analysis it is assumed that dioxygen is reduced by $n=4$ electrons at the ring. This however may vary with the exact reaction conditions and is best analyzed in separate oxygen reduction experiments. ${ }^{50}$ Once the Faradaic efficiency has been determined and the catalyst loading is known a turnover frequency can be extracted from the disk-current.

In the case of $\left[\mathrm{Ru}(\mathrm{L})\left(\mathrm{bpy}-\mathrm{PO}(\mathrm{OH})_{2}\right)\left(\mathrm{OH}_{2}\right)\right]^{2+}$ and $[\mathrm{Ru}(\mathrm{tpy})(\mathrm{bpy}-$ $\left.\left.\mathrm{PO}(\mathrm{OH})_{2}\right)\left(\mathrm{OH}_{2}\right)\right]^{2+}$ anchored via the standard $-\mathrm{PO}(\mathrm{OH})_{2}$ anchoring groups at ITO nanoparticles that in turn are immobilized onto a glassy carbon disk, maximum turnover frequencies of $0.09 \mathrm{~s}^{-1}$ and $0.015 \mathrm{~s}^{-1}$ were found at $1.65 \mathrm{~V}$ versus $\mathrm{NHE}\left(0.1 \mathrm{M} \mathrm{HClO}_{4}\right) \dagger$

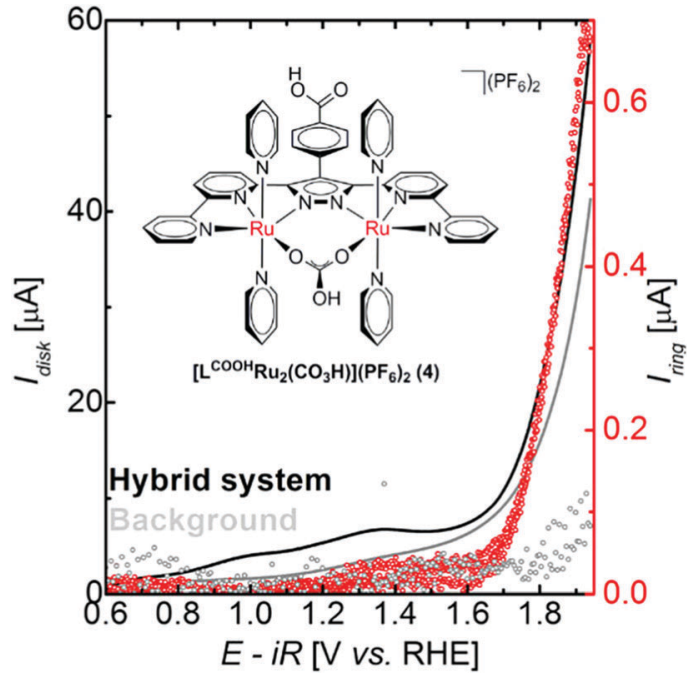

Fig. 5 Rotating ring disk CV measurements of surface-anchored GClmesolTO|[ $\left[{ }^{\mathrm{COOH}} \mathrm{Ru}_{2}\left(\mathrm{CO}_{3} \mathrm{H}\right)\right]\left(\mathrm{PF}_{6}\right)_{2}$ (solid black line) and the blank GCImesolTO electrode (solid gray line) in $0.1 \mathrm{M}$ triflic acid. The corresponding ring currents are shown as red and gray dots respectively. Reprinted with permission from ref. 50. Copyright (2017) American Chemical Society.

with a $50 \%$ and $27 \%$ Faradaic efficiency, respectively $(\mathrm{L}=2,6$ bis(1-methyl-1 $H$-benzimidazol-2-yl)pyridine, tpy = terpyridine, bpy-PO $(\mathrm{OH})_{2}=$ bipyridine-4, $4^{\prime}$-bis(methylenephosphonic acid $){ }^{49}$

Immobilization of $\left[\mathrm{L}^{\mathrm{COOH}} \mathrm{Ru}_{2}\left(\mathrm{CO}_{3} \mathrm{H}\right)\right]\left(\mathrm{PF}_{6}\right)_{2}$ onto a glassy carbon electrode did not result in a massive increase in current with respect to the bare electrode (see Fig. 5). Yet the selectively of the oxygen evolution reaction shifted largely from non-productive redox reactions to the actual formation of $\mathrm{O}_{2}$ (see Fig. 5). ${ }^{50}$ This highlights the importance of establishing which products are formed as the current alone evidently is not sufficient to grasp the full picture.

RRDE experiments have also been employed to determine oxygen formation in the case of $\left[\mathrm{Ru}(\mathrm{bda})\left(\mathrm{P}_{2}-\mathrm{py}\right)\right]^{51}$ and the organocatalyst $N(5)$-ethylflavinium (see Fig. 5, $\mathrm{P}_{2}$-py $=$ (1-(pyridin4-yl)ethane-1,2-diyl)bis(phosphonic acid)). ${ }^{52}$ In the latter example the catalyst was not attached to the disk electrode. To what extent the ring current can be attributed to the reduction of dioxygen or that of partly oxidized catalytic species was in this case not addressed.

\section{Clark electrode}

Similar to RRDE experiments, electrocatalytic oxidation of water can also be combined with a Clark electrode. ${ }^{21,53}$ An advantage of this approach is that the Clark electrode is shielded from the homogeneous catalysts in solution from an oxygen permeable membrane. Consequently, the reduction of dioxygen at the Clark electrode can proceed selectively. The response time of such a system is considerably longer than that of DEMS, OLEMS and RRDE (depending strongly on the exact configuration) but with roughly 20 seconds is still reasonable compared to any headspace analysis technique. ${ }^{54}$ Analysis of the water oxidation reaction mediated by $\left[\operatorname{Ir}\left(\mathrm{Cp}^{*}\right)(\right.$ pyalc $\left.)(\mathrm{OTf})\right]$ at a gold working electrode results in an increase of dioxygen 
concentration of $70 \mu$ mole at an applied potential of $1.7 \mathrm{~V}$ versus NHE (pH 7), whereas only a $36 \mu$ mole increase in dioxygen concentration was observed for the blank gold electrode. ${ }^{21}$ The recorded Faradaic efficiency for the $\left[\operatorname{Ir}\left(\mathrm{Cp}^{*}\right)(\right.$ pyalc)(OTf)] catalyst is relatively poor with $60-70 \%$, yet since a similar efficiency was observed for bare gold, it was suggested that this poor faradaic efficiency is intrinsic to the experimental setup that was used in that particular study.

\section{Detection of catalytic intermediates}

Spectroelectrochemical techniques have been used in various fields to detect redox intermediates. ${ }^{55}$ Especially the combination of the obtained electronic spectra with DFT calculations is becoming a more and more powerful strategy to identify catalytic intermediates and to unravel reaction mechanisms. However, one should be careful in the interpretation of such results as the species detected spectroscopically may not be necessarily relevant in the catalytic mechanism. In the oxygen evolution reaction mediated by molecular catalysts in situ spectroscopy approaches so far have been limited to UV-vis and Raman spectroscopy. Examples of both are described below.

\section{UV-vis spectroscopy}

Spectroelectrochemistry is in particular insightful when dealing with a catalytic species that shows several redox couples in the current-potential diagram. ${ }^{56}$ By applying a potential between these redox couples individual species can be obtained selectively and their spectra recorded by UV-vis spectroscopy. It is important to realize that the actual electron transfer reactions only occur very close to the electrode. The distance in which one can detect species in solution depends on the diffusion constant of the species and on the rate in which the oxidized species reacts away (e.g. via dissociation of dioxygen). ${ }^{57}$ A convenient way to analyze catalytic species is by use of an electrochemical cell, in which the cell volume is small and the electrode surface is very large. ${ }^{58}$ In such a setup, the time required to oxidize a sufficient amount of material to detect it in the bulk is relatively short. Reversibility of the redox couple and the accompanied changes in the UV-vis spectrum in combination with the observation of clear isobestic points are a good indication that the electrochemically formed species are stable. $^{52,59-62}$

In situ UV-vis spectroscopy of the bulk solution has also been employed to show the stability of the catalytic material. This, however, can be tricky. In such long term electrolysis experiments, typically a small decrease in UV absorption is observed, ${ }^{63}$ especially in cases where ligand(s) partly dissociate. ${ }^{64}$ Albeit the reported decrease in activity can be small, one has to keep in mind that decomposition of a small percentage of the molecular water oxidation catalyst at the electrode interface may be enough to account for all catalytic activity. An intriguing example is the case of electrochemical water oxidation in the presence of cobalt polyoxometallates. It was estimated that $4.3 \%$ of free cobalt leaching from the molecular catalyst would be sufficient to account for all catalytic activity in that particular electrochemical experiment. ${ }^{15}$ In an electrolysis experiment in which only material near the electrode surface can undergo redox reactions, the observed catalytic activity may occur through the buildup of a heterogeneous species at the electrode surface without any significant losses in the absorption spectrum of the bulk solution of the (pre)catalyst. Verification that no deposition has taken place at the electrode interface is highly recommended.

The interpretation of spectra becomes significantly easier when the molecular catalysts are attached to a transparent ITO or FTO electrode. In such a configuration the UV-vis spectrum exclusively shows spectra of species that can undergo redox reactions. Nano-ITO can be used to increase the surface area and allows for attachment of a sufficient amount of material. ${ }^{49}$ An illustrated example is depicted in Fig. 6. Stepwise oxidation of $\left[\mathrm{Ru}(\mathrm{bda})\left(\mathrm{P}_{2} \text {-py }\right)_{2}\right]$ (bda $=\left[2,2^{\prime}\right.$-bipyridine $]-6,6^{\prime}$-dicarboxylic acid, $\quad \mathrm{P}_{2}$-py $=$ (1-(pyridin-4-yl)ethane-1,2-diyl)bis(phosphonic acid)) was followed by in situ spectroscopy showing isobestic points for the transitions related to the first two waves in the cyclic voltammetry (Fig. 6, waves I and II). ${ }^{51}$ The combination of UV-vis spectroscopy and TD-DFT calculations allowed the authors to assign the spectra of the transient species to $\mathrm{Ru}^{\mathrm{III}}-\mathrm{O}-\mathrm{Ru}^{\mathrm{III}}$ and $\mathrm{Ru}^{\mathrm{IV}}-\mathrm{O}-\mathrm{Ru}^{\mathrm{IV}}$ species, rather than their mononuclear analogs. Further oxidation of the dinuclear $\mathrm{Ru}^{\mathrm{IV}}$ species triggers the oxygen evolution reaction (wave III).

Treatment of nanoITO electrodes with a dinuclear iridium(Iv) precursor obtained from $\left[\operatorname{Ir}\left(\mathrm{Cp}^{*}\right)(\right.$ pyalc $\left.)\left(\mathrm{CF}_{3} \mathrm{COO}\right)\right]$ and periodate results in the immobilization of dinuclear iridium(Iv) species that still carry the organic pyalc ligands. ${ }^{65}$ UV spectroscopy was successfully used to show that the attachment of the complex on nanoITO is rather stable. Only at very alkaline conditions the disappearance of the UV signal was observed. When a potential was applied between 0.5 and $1.4 \mathrm{~V}$ versus NHE a wave at $580 \mathrm{~nm}$ was observed which is typical for an iridium(Iv) species (Fig. 7). This value corresponds well with the $608 \mathrm{~nm}$ that was found for

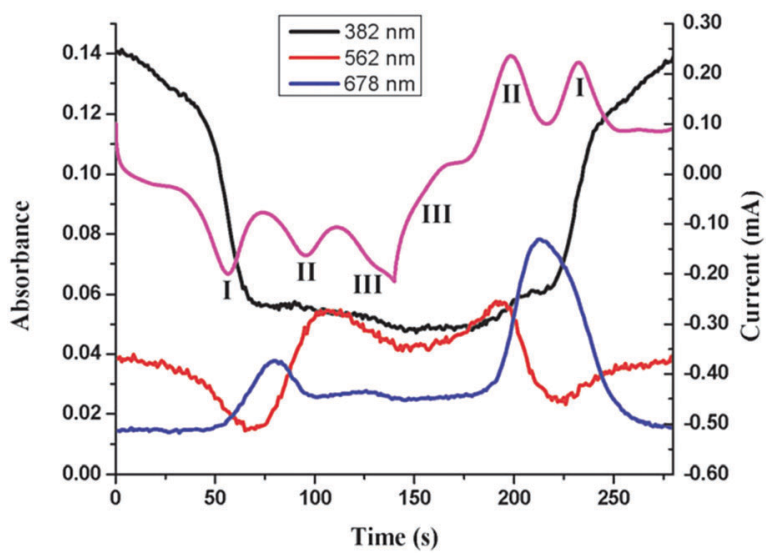

Fig. 6 Electrochemistry in combination with UV spectroscopy of [Ru(bda) $\left.\left(\mathrm{P}_{2}-\text { py }\right)_{2}\right]$ on nanolTO in $0.1 \mathrm{M} \mathrm{HClO}_{4}$. In pink is given the current as a function of time, while scanning between $0.2 \mathrm{~V}$ (start and finish) and $1.4 \mathrm{~V}$ versus $\mathrm{NHE}$ (middle) at $10 \mathrm{mV} \mathrm{s}^{-1}$. The UV spectra of the catalytic intermediates are followed at $678 \mathrm{~nm}$ (assigned to a $\mathrm{Ru}^{\text {III ORu }} \mathrm{u}^{\mathrm{II}}$ species), $562 \mathrm{~nm}$ (overlaying MCLT transition of the Ru" complex and the Ru ${ }^{\text {IV }}-\mathrm{O}-\mathrm{Ru}^{\mathrm{IV}}$ complex) and $382 \mathrm{~nm}$ (MCLT transitions of the Ru ${ }^{\prime \prime}$ complex). Reproduced from ref. 51 with permission from the Royal Society of Chemistry. 


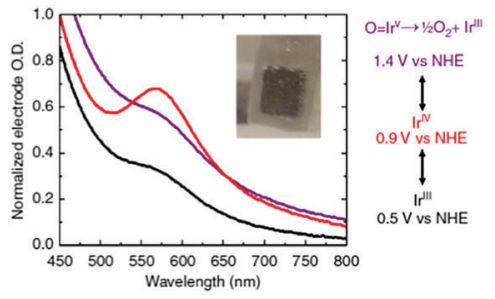

Fig. 7 The in situ UV spectrum of a deposited iridium(IV) pyalc complex at the + III oxidation state (black), the +IV oxidation state (red) and catalytic conditions (purple). Adapted from ref. 65 with permission from the Nature Publishing Group.

the parent iridium(Iv) precursor in solution. Below $0.5 \mathrm{~V}$ versus NHE the iridium sites are reduced to the +III oxidation state. Above 1.4 V versus NHE the oxygen evolution reaction is triggered, probably via initial oxidation of iridium to the $+\mathrm{V}$ oxidation state.

\section{Vibrational spectroscopy}

Thus far on-line vibrational studies of catalytic intermediates in the electrocatalytic water oxidation reaction have been restricted to Surface Enhanced Raman Spectroscopy (SERS) studies. SERS is a non-linear technique that can be extremely sensitive. ${ }^{66}$ The main advantage of this Raman approach is that one can use particular surfaces (e.g. Au, Ag, Pt) both as the working electrode and for surface enhancement of the Raman signals. ${ }^{67}$ This approach has been used frequently to study molecular catalysts for the oxygen reduction reaction. ${ }^{68,69}$ In particular partly reduced dioxygen (and likewise partly oxidized aqua species) can easily be detected by Raman techniques and identified by ${ }^{18} \mathrm{O}$ and ${ }^{2} \mathrm{H}$ labeling experiments. ${ }^{70}$ Under more oxidative conditions that are compulsory to study the water oxidation reaction, SERS analysis of catalytic intermediates is more troublesome as formation of a metal oxide layer desensitizes the sample for Raman activity. ${ }^{71}$ Such phenomena are for example visible in Fig. 8 where the gold

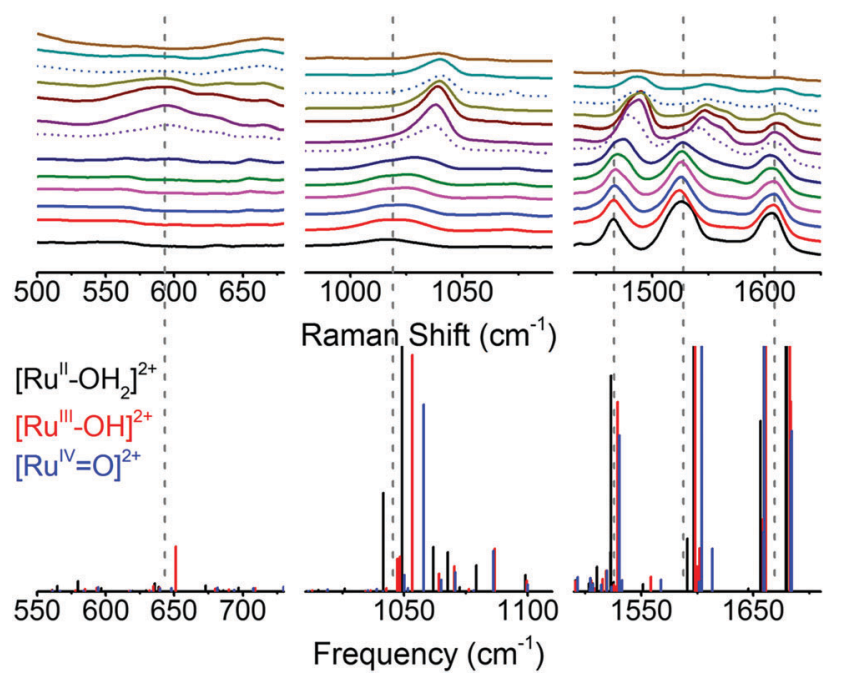

Fig. 8 Potential dependent SERS response of dropcast $\left[\mathrm{Ru}(\mathrm{cy})(\mathrm{bpc})\left(\mathrm{OH}_{2}\right)\right]^{2+}$ on a roughened gold electrode (above) and calculated spectra using TD-DFT (below). The potentials vary from $-0.4 \mathrm{~V}$ to $0.8 \mathrm{~V}$ (in steps of $100 \mathrm{mV}$ from the bottom to the top) versus NHE ( $\mathrm{pH}=7.0)$. $\dagger$ Reprinted with permission from ref. 38. Copyright (2017) American Chemical Society. surface becomes desensitized above $0.8 \mathrm{~V}$ versus $\mathrm{NHE}(\mathrm{pH} 7) . \dagger$ Hence SERS is predominantly useful to detect catalytic intermediates that are formed at milder potentials than the potential determining step. Detection of catalytic species that are formed at the potential determining step is difficult nonetheless as typically these species react away rapidly upon release of dioxygen.

Oxidation of $\left[\mathrm{Ru}(\mathrm{cy})(\mathrm{bpc})\left(\mathrm{OH}_{2}\right)\right]^{2+}$ occurs from the ruthenium + II oxidation state to the + III and + IV oxidation states at $0.15 \mathrm{~V}$ and $0.55 \mathrm{~V}$ versus NHE respectively. ${ }^{38}$ These transitions from $\mathrm{Ru}^{\mathrm{II}}\left(\mathrm{OH}_{2}\right)$ to $\mathrm{Ru}^{\mathrm{III}}(\mathrm{OH})$ and $\mathrm{Ru}^{\mathrm{IV}}=\mathrm{O}$ can be observed in the Raman spectrum of $[\mathrm{Ru}(\mathrm{cy})(\mathrm{bpc})(\mathrm{Cl})]^{2+}$ dropcast on a roughened gold electrode, showing clear domains below $0.1 \mathrm{~V}$, between $0.2 \mathrm{~V}$ and $0.5 \mathrm{~V}$, and above $0.6 \mathrm{~V}$ (Fig. 8). Whereas the $\mathrm{Ru}-\mathrm{O}$ signal of $\mathrm{Ru}^{\mathrm{II}}\left(\mathrm{OH}_{2}\right)$ is expected at very low frequencies and therefore was not detected experimentally, a clear signal was observed at $570 \mathrm{~cm}^{-1}$ corresponding to the $\mathrm{Ru}-\mathrm{O}$ stretch of $\mathrm{Ru}^{\mathrm{III}}(\mathrm{OH})$. The weak stretch for $\mathrm{Ru}=\mathrm{O}$ was expected at 830 on the basis of TD-DFT calculations and similar to other $\mathrm{Ru}=\mathrm{O}$ species was not detected. The change in the oxidation state of the ruthenium center is in line with shifts of the $\mathrm{Ru}-\mathrm{N}$ $\left(\sim 1050 \mathrm{~cm}^{-1}\right)$ and bipyridine $\mathrm{C}-\mathrm{C}$ signals $\left(\sim 1500 \mathrm{~cm}^{-1}\right)$ to higher wavenumbers. Above the onset of gold oxidation at $0.8 \mathrm{~V}$ versus NHE the Raman signals broaden and weaken significantly. Cycling the potential back to its starting position regenerates the Raman spectrum of $\mathrm{Ru}^{\mathrm{II}}\left(\mathrm{OH}_{2}\right)$ and illustrates that the catalytic material is stable under the conditions employed. ${ }^{38}$

Reversible oxidation of $\left[\operatorname{Ir}\left(\mathrm{Cp}^{*}\right)\left(\mathrm{Me}_{2}-\mathrm{NHC}\right)(\mathrm{OH})_{2}\right]$ was observed at $1.0 \mathrm{~V}$ versus $\mathrm{RHE}^{36}$ Above $0.9 \mathrm{~V}$ a Raman signal was found at $560 \mathrm{~cm}^{-1}$, which shifts to $520 \mathrm{~cm}^{-1}$ in ${ }^{18} \mathrm{O}$ labeled water. Since no changes are observed in deuterated solvent and the $\sim 40 \mathrm{~cm}^{-1}$ shift fits well with the formation of a bridging oxide, ${ }^{70}$ the $\mu$-O bridged iridium(Iv) species $\left[\left\{\operatorname{Ir}\left(\mathrm{Cp}^{*}\right)\left(\mathrm{Me}_{2} \mathrm{NHC}\right)\right\}_{2}(\mu-\mathrm{O})_{2}\right]^{2+}$ was proposed as a catalytic intermediate under electrochemical conditions in analogy with early assignment of a similar $\mu-\mathrm{O}$ bridged iridium dimer as a catalytic intermediate in the water oxidation reaction in the presence of $\left[\operatorname{Ir}\left(\mathrm{Cp}^{*}\right)(\right.$ pyalc $\left.)\left(\mathrm{CF}_{3} \mathrm{COO}\right)\right] .^{27}$ However, a species bearing a single $\mu$-O ligand as was postulated more recently in the case of $\left[\operatorname{Ir}\left(\mathrm{Cp}^{*}\right)(\right.$ pyalc $\left.)\left(\mathrm{CF}_{3} \mathrm{COO}\right)\right]$ on the basis of ex situ X-ray absorption spectroscopy ${ }^{31}$ would fit with such Raman observations as well. A further increase of the potential above $1.5 \mathrm{~V}$ versus RHE results in an oxygen evolution reaction. ${ }^{28,36}$

\section{Conclusions}

In operando studies combined with electrochemistry allow one to obtain structural information regarding the "true" catalytic species under well-defined and meaningful conditions in the water oxidation reaction. Especially a combination of in operando techniques with further ex situ studies and density functional theory can be very powerful for the determination of the "true" catalytic species, structure-activity relationships and catalytic mechanisms. Recently, considerable advances have been made in this area and microbalance, mass spectrometry, Clark electrode, RRDE electrode, UV-vis spectroscopy and surface enhanced Raman 
spectroscopy all have successfully been used in several illustrative examples and have led to important new insights. Other techniques such as IR spectroscopy and various X-ray spectroscopy techniques ${ }^{72}$ are yet to be explored in an electrochemical oxygen evolution context employing a molecular catalyst.

\section{Conflicts of interest}

There are no conflicts to declare.

\section{Acknowledgements}

The Netherlands' Organisation for Scientific Research (NWO) and the European Research Council (ERC) are kindly acknowledged for funding.

\section{Notes and references}

1 H. L. Tuller, Materials for Renewable and Sustainable Energy, 2017, vol. 6.

2 S. Fukuzumi and D. C. Hong, Eur. J. Inorg. Chem., 2014, 645-659.

3 B. Limburg, E. Bouwman and S. Bonnet, Coord. Chem. Rev., 2012, 256, 1451-1467.

4 J. W. Vickers, H. J. Lv, J. M. Sumliner, G. B. Zhu, Z. Luo, D. G. Musaev, Y. V. Geletii and C. L. Hill, J. Am. Chem. Soc., 2013, 135, 14110-14118.

5 A. R. Parent, R. H. Crabtree and G. W. Brudvig, Chem. Soc. Rev., 2013, 42, 2247-2252.

6 J. J. Concepcion, M. K. Tsai, J. T. Muckerman and T. J. Meyer, J. Am. Chem. Soc., 2010, 132, 1545-1557.

7 L. P. Tong and R. P. Thummel, Chem. Sci., 2016, 7, 6591-6603.

8 D. J. Wasylenko, C. Ganesamoorthy, M. A. Henderson and C. P. Berlinguette, Inorg. Chem., 2011, 50, 3662-3672.

9 D. G. H. Hetterscheid and J. N. H. Reek, Eur. J. Inorg. Chem., 2014, 742-749.

10 M. Yoshida, S. Masaoka, J. Abe and K. Sakai, Chem. - Asian J., 2010, 5, 2369-2378.

11 T. J. Demars, M. K. Bera, S. Seifert, M. R. Antonio and R. J. Ellis, Angew. Chem., Int. Ed., 2015, 54, 7534-7538.

12 Z. Codola, L. Gomez, S. T. Kleespies, L. Que, M. Costas and J. LloretFillol, Nat. Commun., 2015, 6, 5865.

13 D. C. Hong, M. Murakami, Y. Yamada and S. Fukuzumi, Energy Environ. Sci., 2012, 5, 5708-5716.

14 S. J. Folkman and R. G. Finke, ACS Catal., 2017, 7, U7-U922.

15 J. J. Stracke and R. G. Finke, J. Am. Chem. Soc., 2011, 133, 14872-14875.

16 D. A. Buttry and M. D. Ward, Chem. Rev., 1992, 92, 1355-1379.

17 A. M. Bond, A. Lamprecht, V. Tedesco and F. Marken, Inorg. Chim. Acta, 1999, 291, 21-31.

18 G. Sauerbrey, Z. Phys., 1959, 155, 206-222.

19 M. R. Deakin and O. Melroy, J. Electroanal. Chem., 1988, 239, 321-331.

20 C. J. M. van der Ham, F. Isik, T. W. G. M. Verhoeven, J. W. Niemantsverdriet and D. G. H. Hetterscheid, Catal. Today, 2017, 290, 33-38.

21 N. D. Schley, J. D. Blakemore, N. K. Subbaiyan, C. D. Incarvito, F. D'Souza, R. H. Crabtree and G. W. Brudvig, J. Am. Chem. Soc., 2011, 133, 10473-10481.

22 J. D. Blakemore, N. D. Schley, G. W. Olack, C. D. Incarvito, G. W. Brudvig and R. H. Crabtree, Chem. Sci., 2011, 2, 94-98.

23 J. D. Blakemore, N. D. Schley, M. N. Kushner-Lenhoff, A. M. Winter, F. D'Souza, R. H. Crabtree and G. W. Brudvig, Inorg. Chem., 2012, 51, 7749-7763.

24 J. D. Blakemore, M. W. Mara, M. N. Kushner-Lenhoff, N. D. Schley, S. J. Konezny, I. Rivalta, C. F. A. Negre, R. C. Snoeberger, O. Kokhan, J. Huang, A. Stickrath, L. A. Tran, M. L. Parr, L. X. Chen, D. M. Tiede, V. S. Batista, R. H. Crabtree and G. W. Brudvig, Inorg. Chem., 2013, 52, 1860-1871.

25 C. Zuccaccia, G. Bellachioma, O. Bortolini, A. Bucci, A. Savini and A. Macchioni, Chem. - Eur. J., 2014, 20, 3446-3456.
26 C. Zuccaccia, G. Bellachioma, S. Bolano, L. Rocchigiani, A. Savini and A. Macchioni, Eur. J. Inorg. Chem., 2012, 1462-1468.

27 U. Hintermair, S. W. Sheehan, A. R. Parent, D. H. Ess, D. T. Richens, P. H. Vaccaro, G. W. Brudvig and R. H. Crabtree, J. Am. Chem. Soc., 2013, 135, 10837-10851.

28 D. G. H. Hetterscheid, C. J. M. van der Ham, O. Diaz-Morales, M. W. G. M. Verhoeven, A. Longo, D. Banerjee, J. W. Niemantsverdriet, J. N. H. Reek and M. C. Feiters, Phys. Chem. Chem. Phys., 2016, 18, 10931-10940.

29 M. de Respinis, K. S. Joya, H. J. M. De Groot, F. D’Souza, W. A. Smith, R. van de Krol and B. Dam, J. Phys. Chem. C, 2015, 119, 7275-7281.

30 J. M. Thomsen, S. W. Sheehan, S. M. Hashmi, J. Campos, U. Hintermair, R. H. Crabtree and G. W. Brudvig, J. Am. Chem. Soc., 2014, 136, 13826-13834.

31 K. R. Yang, A. J. Matula, G. Kwon, J. Y. Hong, S. W. Sheehan, J. M. Thomsen, G. W. Brudvig, R. H. Crabtree, D. M. Tiede, L. X. Chen and V. S. Batista, J. Am. Chem. Soc., 2016, 138, 5511-5514.

32 C. C. L. McCrory, S. H. Jung, J. C. Peters and T. F. Jaramillo, J. Am. Chem. Soc., 2013, 135, 16977-16987.

33 M. Li, K. Takada, J. I. Goldsmith and S. Bernhard, Inorg. Chem., 2016, 55, 518-526.

34 H. Baltruschat, J. Am. Soc. Mass Spectrom., 2004, 15, 1693-1706.

35 A. H. Wonders, T. H. M. Housmans, V. Rosca and M. T. M. Koper, J. Appl. Electrochem., 2006, 36, 1215-1221.

36 O. Diaz-Morales, T. J. P. Hersbach, D. G. H. Hetterscheid, J. N. H. Reek and M. T. M. Koper, J. Am. Chem. Soc., 2014, 136, 10432-10439.

37 K. G. Kottrup and D. G. H. Hetterscheid, Chem. Commun., 2016, 52, 2643-2646.

38 J. M. de Ruiter, R. L. Purchase, A. Monti, C. J. M. van der Ham, M. P. Gullo, K. S. Joya, M. D'Angelantonio, A. Barbieri, D. G. H. Hetterscheid, H. J. M. de Groot and F. Buda, ACS Catal., 2016, 6, 7340-7349.

39 P. Abril, M. P. del Rio, C. Tejel, T. W. G. M. Verhoeven, J. W. H. Niemantsverdriet, C. J. M. Van der Ham, K. G. Kottrup and D. G. H. Hetterscheid, ACS Catal., 2016, 6, 7872-7875.

40 N. Mirbagheri, J. Chevallier, J. Kibsgaard, F. Besenbacher and E. E. Ferapontova, ChemPhysChem, 2014, 15, 2844-2850.

41 A. M. Ullman, Y. Liu, M. Huynh, D. K. Bediako, H. S. Wang, B. L. Anderson, D. C. Powers, J. J. Breen, H. D. Abruna and D. G. Nocera, J. Am. Chem. Soc., 2014, 136, 17681-17688.

42 K. G. Gallagher and T. F. Fuller, Phys. Chem. Chem. Phys., 2009, 11, 11557-11567.

43 O. Diaz-Morales, F. Calle-Vallejo, C. de Munck and M. T. M. Koper, Chem. Sci., 2013, 4, 2334-2343.

44 M. W. Kanan and D. G. Nocera, Science, 2008, 321, 1072-1075.

45 A. I. Nguyen, M. S. Ziegler, P. Ona-Burgos, M. Sturzbecher-Hohne, W. Kim, D. E. Bellone and T. D. Tilley, J. Am. Chem. Soc., 2015, 137, 12865-12872.

46 P. F. Smith, L. Hunt, A. B. Laursen, V. Sagar, S. Kaushik, K. U. D. Calvinho, G. Marotta, E. Mosconi, F. De Angelis and G. C. Dismukes, J. Am. Chem. Soc., 2015, 137, 15460-15468.

47 A. Genoni, G. La Ganga, A. Volpe, F. Puntoriero, M. Di Valentin, M. Bonchio, M. Natali and A. Sartorel, Faraday Discuss., 2015, 185, 121-141.

48 A. J. Bard and L. R. Faulkner, Electrochemical Methods, Wiley, New York, 1980.

49 J. J. Concepcion, R. A. Binstead, L. Alibabaei and T. J. Meyer, Inorg. Chem., 2013, 52, 10744-10746.

50 J. Odrobina, J. Scholz, A. Pannwitz, L. Francas, S. Dechert, A. Llobet, C. Jooss and F. Meyer, ACS Catal., 2017, 7, 2116-2125.

51 J. J. Concepcion, D. K. Zhong, D. J. Szalda, J. T. Muckerman and E. Fujita, Chem. Commun., 2015, 51, 4105-4108.

52 E. Mirzakulova, R. Khatmullin, J. Walpita, T. Corrigan, N. M. VargasBarbosa, S. Vyas, S. Oottikkal, S. F. Manzer, C. M. Hadad and K. D. Glusac, Nat. Chem., 2012, 4, 794-801.

53 S. Pattanayak, D. R. Chowdhury, B. Garai, K. K. Singh, A. Paul, B. B. Dhar and S. Sen Gupta, Chem. - Eur. J., 2017, 23, 3414-3424.

54 D. B. Grotjahn, D. B. Brown, J. K. Martin, D. C. Marelius, M. C. Abadjian, H. N. Tran, G. Kalyuzhny, K. S. Vecchio, Z. G. Specht, S. A. Cortes-Llamas, V. Miranda-Soto, C. van Niekerk, C. E. Moore and A. L. Rheingold, J. Am. Chem. Soc., 2011, 133, 19024-19027.

55 W. Kaim and J. Fiedler, Chem. Soc. Rev., 2009, 38, 3373-3382.

56 T. E. Rosser and E. Reisner, ACS Catal., 2017, 7, 3131-3141. 
57 C. Costentin, S. Drouet, M. Robert and J. M. Saveant, J. Am. Chem. Soc., 2012, 134, 19949-19950.

58 M. Krejcik, M. Danek and F. Hartl, J. Electroanal. Chem., 1991, 317, 179-187.

59 D. E. Polyansky, J. T. Muckerman, J. Rochford, R. F. Zong, R. P. Thummel and E. Fujita, J. Am. Chem. Soc., 2011, 133, 14649-14665.

60 J. Mola, C. Dinoi, X. Sala, M. Rodriguez, I. Romero, T. Parella, X. Fontrodona and A. Llobet, Dalton Trans., 2011, 40, 3640-3646.

$61 \mathrm{~J}$. Honta, S. Tajima, T. Sato, K. Saito, T. Yui and M. Yagi, J. Photochem. Photobiol., A, 2015, 313, 126-130.

62 W. Sinha, M. G. Sommer, N. Deibel, F. Ehret, M. Bauer, B. Sarkar and S. Kar, Angew. Chem., Int. Ed., 2015, 54, 13769-13774.

63 Y. Z. Han, Y. Z. Wu, W. Z. Lai and R. Cao, Inorg. Chem., 2015, 54, 5604-5613.

64 H. T. Lei, A. Han, F. W. Li, M. N. Zhang, Y. Z. Han, P. W. Du, W. Z. Lai and R. Cao, Phys. Chem. Chem. Phys., 2014, 16, 1883-1893.
65 S. W. Sheehan, J. M. Thomsen, U. Hintermair, R. H. Crabtree, G. W. Brudvig and C. A. Schmuttenmaer, Nat. Commun., 2015, 6, 6469.

66 H. W. Liu, L. Zhang, X. Y. Lang, Y. Yamaguchi, H. S. Iwasaki, Y. S. Inouye, Q. K. Xue and M. W. Chen, Sci. Rep., 2011, 1, 112-116.

67 D. Y. Wu, J. F. Li, B. Ren and Z. Q. Tian, Chem. Soc. Rev., 2008, 37, 1025-1041.

68 S. Mukherjee, S. Bandyopadhyay, S. Chatterjee and A. Dey, Chem. Commun., 2014, 50, 12304-12307.

69 S. Mukherjee, A. Mukherjee, A. Bhagi-Damodaran, M. Mukherjee, Y. Lu and A. Dey, Nat. Commun., 2015, 6, 8467-8475.

70 L. M. Mirica, X. Ottenwaelder and T. D. P. Stack, Chem. Rev., 2004, 104, 1013-1045.

71 M. Erol, Y. Han, S. K. Stanley, C. M. Stafford, H. Du and S. Sukhishvili, J. Am. Chem. Soc., 2009, 131, 7480-7481.

72 C. H. van Oversteeg, H. Q. Doan, F. M. de Groot and T. Cuk, Chem. Soc. Rev., 2017, 46, 102-125. 